\title{
Experimental Methods for Crop-Weed Competition Studies
}

\section{Importance of Crop-Weed Competition Studies}

Clarence J. Swanton, Roger Nkoa, and Robert E. Blackshaw*
The annual global economic loss caused by weeds has been estimated at more than $\$ 100$ billion U.S. dollars (Appleby et al. 2000). Additionally, worldwide annual herbicide sales are in the range of U.S. $\$ 25$ billion (Agrow 2003). In light of these large dollar figures, it becomes clear that a greater understanding of crop-weed interactions is essential in order to develop cost-effective and sustainable weed management practices.

Crop-weed competition studies can provide valuable information to farmers and land managers on whether weed control is warranted, and if so, what is the optimal timing to implement weed control practices. For example, the development of economic weed thresholds aids farmers in making decisions about the necessity of weed control and the cost effectiveness of various weed control options. Knowledge of critical periods for weed control assists growers in determining when, or when not, to pursue further weed control measures to protect crop yield.

Crop-weed competition studies can provide information on the merits of various components of a cropping system. Crop rotation, intercropping, seeding rates, row spacing, and fertilizer placement are components of a cropping system that will invariably influence the competitiveness of the crop or the weed, or both. Competitive cropping systems that enhance crop establishment, rate of leaf appearance, and canopy cover will reduce weed competition and costs associated with weed control.

Competition studies can also contribute to our understanding of how species fitness is influenced by selection pressures imposed by the agronomic practices of the cropping system. For example, the fitness of herbicide-resistant weed biotypes compared with susceptible weed populations can

DOI: 10.1614/WS-D-13-00062.1

* First and second authors: Weed Scientist and Research Associate, University of Guelph, 50 Stone Road East, Guelph, Ontario N1G 2W1, Canada; third author: Weed Scientist, Agriculture and Agri-Food Canada, Lethbridge Research Center, 5403 First Avenue South, Lethbridge, Alberta T1J 4B1, Canada. Corresponding author's E-mail: robert.blackshaw@agr.gc.ca provide important biological information on the physiological costs associated with the herbicideresistant trait. This knowledge can be very useful in predicting the invasive potential of resistant weed biotypes over time and may provide insight for effective control strategies.

\section{Factors Affecting Crop-Weed Competition}

The effect of weed competition on crop yield is driven by three major variables. The most important variable to record in any competition study is the time of weed emergence relative to the crop (Dew 1972; Kropff and Spitters 1991; O’Donovan et al. 1985). Without knowledge of this information, it is difficult to make sense of yield losses presented in many published plant competition papers. Weeds that emerge with or before the crop are by far the most competitive and result in the greatest yield loss. For example, threshold levels of redroot pigweed (Amaranthus retroflexus L.), barnyardgrass (Echinochloa crus-galli L.), common ragweed (Ambrosia artemisiifolia L.), and velvetleaf (Abutilon theophrasti Medic.) in corn (Zea mays L.), soybean [Glycine max (L.) Merr.], and dry bean (Phaseolus vulgaris L.) may be 2 to 10 times higher for weeds emerging 3 to $4 \mathrm{wk}$ after the crop compared with those that emerge with the crop (Cardina et al. 1995; Dieleman et al. 1996; Knezevic et al. 1994). Weeds that emerge later than the crop are much less competitive in terms of crop yield loss but still may be considered problematic if they influence crop harvestability or reduce crop quality.

Weed seedling density is the second most important variable, as clearly there is a relationship between weed density and duration of interference. The length of a critical period for weed control varies with density just as density thresholds vary with time of weed emergence relative to the crop (Dunan et al. 1995).

Thirdly, weed species may differ in competitive ability based on such traits as rapid leaf area development, high-density root systems, plant height, etc. Life cycles, reproductive strategies, and morphological features are important traits in 
determining the competitive ability of individual weed species.

Resource-Dependent Processes. Competition can be viewed as a series of interrelated physiological and morphological changes that occur as a result of both resource-dependent and resource-independent processes (Harper 1977). The vast majority of published plant competition articles have focussed on resource-dependent processes such as competition for limiting resources such as water, nutrients, and light. The competitive ability of crops and weeds is determined by physiological and morphological attributes that allow them to explore, capture, and exploit available resources. For example, in a mixed canopy of crop and weeds, light capture efficiency is a function of light interception, which is determined by leaf area index, height, and light absorption efficiency of the leaves (i.e., leaf angular orientation, thickness, vertical leaf area distribution).

Nitrogen, phosphorus, and potassium are considered the most limiting nutrients in most terrestrial ecosystems (Vitousek and Howarth 1991; Walker and Syers 1976). The competitive ability of crops and weeds for nutrient uptake in agricultural ecosystems will be determined primarily by their intrinsic nutrient requirements and uptake efficiencies. The latter are a function of root length densities and efficiency of nutrient transmembrane transporters. Thus, species with a relatively low nutrient requirement, extensive root system, and effective membrane transporters will have a competitive advantage in a nutrient-limited environment.

Crops and weeds also compete for water in rainfed agricultural systems. Water is one of the most important resources required for plant growth, and water stress results in reduced plant photosynthesis, wilting, and nutrient deficiencies. The importance of water competition is determined by the length, magnitude, and timing of the drought period as well as soil attributes (water holding capacity, texture, structure, hydraulic conductivity) and plant traits (root structure and density, drought tolerance, water-use efficiency).

Resource-Independent Processes. Resource-independent effects such as hormonal and light quality signals can also play an important role in determining the outcome of crop-weed competition. The plant's ability to detect signals can be viewed within the context of competition as a communication pathway that may allow a plant to prepare, physiologically or morphologically, a preemptive response to impending competition (Ballaré 1999; Ballaré et al. 1990; Smith and Whitelam 1997). Photosensory systems allow plants to monitor changes in light wavelength, intensity, and direction (Quail 2002; Smith 2000). This ability provides crop plants with environmental cues that regulate their biological clock with respect to phenological development. Detection of the quantity and quality of incoming radiation provides key information that can affect seed germination, seedling establishment, flowering timing, tuberization, bud dormancy, and partitioning of resources to root, stem, and reproductive organs.

The triggering of a preemptive response to impending weed competition suggests that physiological and subsequent morphological changes can occur in the crop plant well in advance of the onset of direct competition for light, water, and nutrients. Morphological changes include an increase in stem elongation and a reduction in stem diameter, rate of leaf appearance, and shoot and root biomass (Kasperbauer and Karlen 1986; Page et al. 2010; Rajcan and Swanton 2001). It has been shown that shade-avoidance responses by some crops in the absence of actual light competition affected components of yield such as kernel number in corn (Page et al. 2010) and tiller number in barley (Hordeum vulgare L.) (Skinner and Simmons 1993) and grasses (Casal et al. 1987; Kasperbauer and Karlen 1986).

\section{Experimental Designs to Study Crop- Weed Competition}

The method that an experimenter chooses to study weed competition is dependent on the hypothesis being tested. Clearly, both field and greenhouse studies can be designed to test for either resource-dependent or resource-independent processes. For this methodology article we will focus on experimental designs that have traditionally been used to provide insight into competitive crop and weed interactions under field conditions.

Crop and weed competition studies conducted under field conditions are invariably influenced by the environment, soil type, plant density, spatial arrangement, and proportion of each species in the mixture. Thus, several experimental methods have been developed that attach different levels of importance to these variables (Harper 1977; Maxwell and O'Donovan 2007; Radosevich 1987; Rejmánek et al. 1989). Although most experimental 
methods can estimate the response to competition between crops and weeds, density, proportion, and spatial arrangement will most likely influence the ability of the design to distinguish between intraand interspecific competition and to determine threshold levels of competition. Consequently, researchers should consider and control these factors in competition studies to avoid issues such as experimental error, inaccuracy, and misinterpretation of the results. In this manuscript we will explore some of the most common experimental designs used in crop-weed competition studies and discuss their respective advantages and disadvantages. Each experimental design deals with plant density, spatial arrangement, and proportion of competing plants in different ways. Finally, remember that a clear hypothesis is essential to choosing the most suitable experimental design; a novel hypothesis based on the published literature and observations should always be the first step in conducting any crop-weed competition study.

Additive Design. Also known as partial additive (Rejmánek et al. 1989), this is the most commonly used experimental design to study the outcome of crop-weed competition. Crop density is held constant while weed density is changed (Figures 1a and $1 \mathrm{~b}$ ). It is relevant to most agricultural situations where the crop occurs at one reasonably uniform density and weed density varies across landscapes, over years, or with various weed control and crop production practices.

In this experimental design, the percentage crop yield loss with increasing weed density is calculated by dividing the yield at each weed density by the weed-free yield. Data are most commonly fitted to a nonlinear regression model (rectangular hyberbola):

$$
\mathrm{YL}=i d /(1+i d / a) \text {, }
$$

where $\mathrm{YL}$ is percent yield loss, $d$ is weed density, $i$ is the percentage yield loss per unit weed density as $d$ approaches zero, and $a$ is the maximum or asymptotic yield loss as $d$ approaches infinity (Cousens 1985).

\section{Advantages}

- Easy to establish under field conditions

- Most suitable to determine potential crop yield losses from weeds (Blackshaw et al. 1981; Cousens 1985)

- Useful to study the effect of relative times of emergence of weeds and crops on competitive outcomes (Blackshaw 1993; O’Donovan et al. 1985) (a)
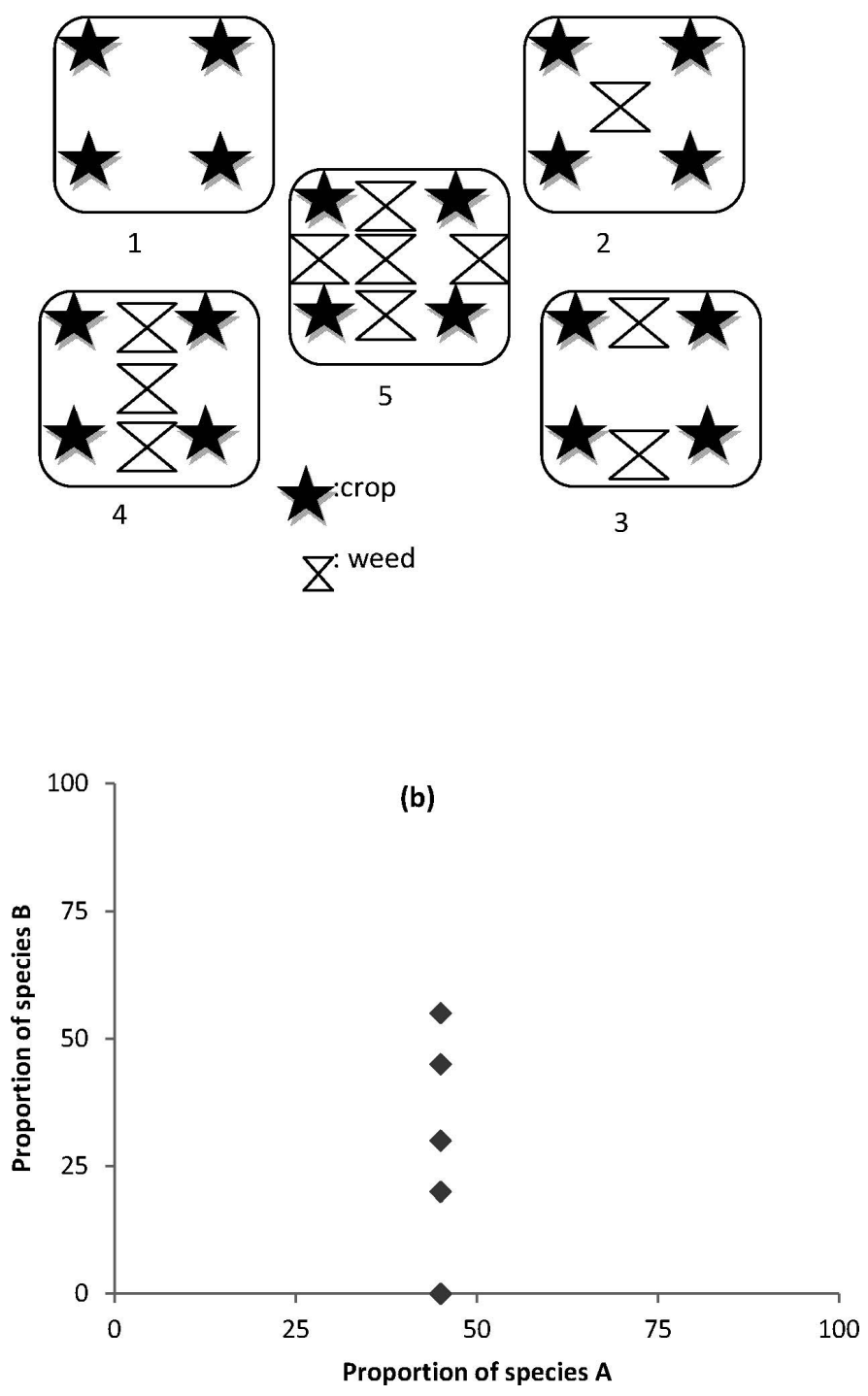

Figure 1. An example of layout (a) and relative densities (b) of an additive experiment with the use of two plant species. Note proportion of species A is held constant in (b).

- Appropriate design for determination of economic weed thresholds (Oliver 1988; Swanton et al. 1999; Weaver and Ivany 1998)

\section{Disadvantages}

- The simultaneous change in proportion and total plant density makes it difficult to determine specific plant interactions and gain insight on competition processes

- Results are dependent on local edaphic and environmental conditions and thus care must be taken in extrapolating results to broad geographic areas

Replacement Series. The replacement-series design (substitutive experiment) was developed to over- 


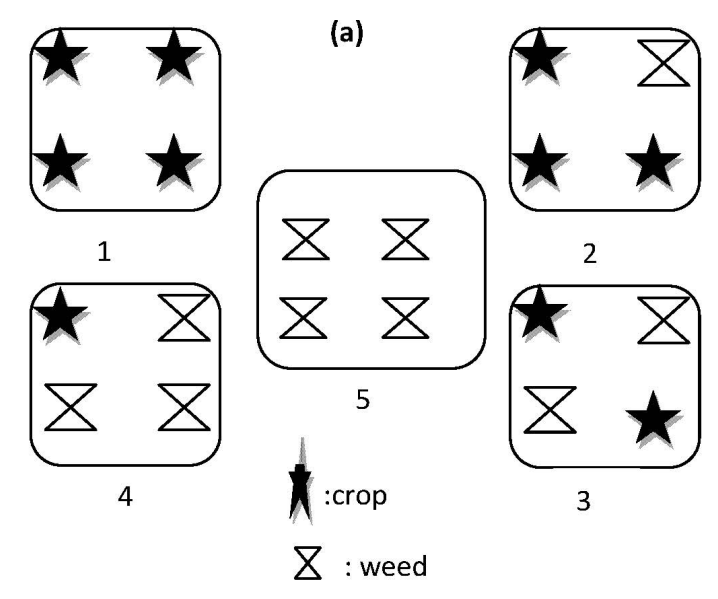

(b)

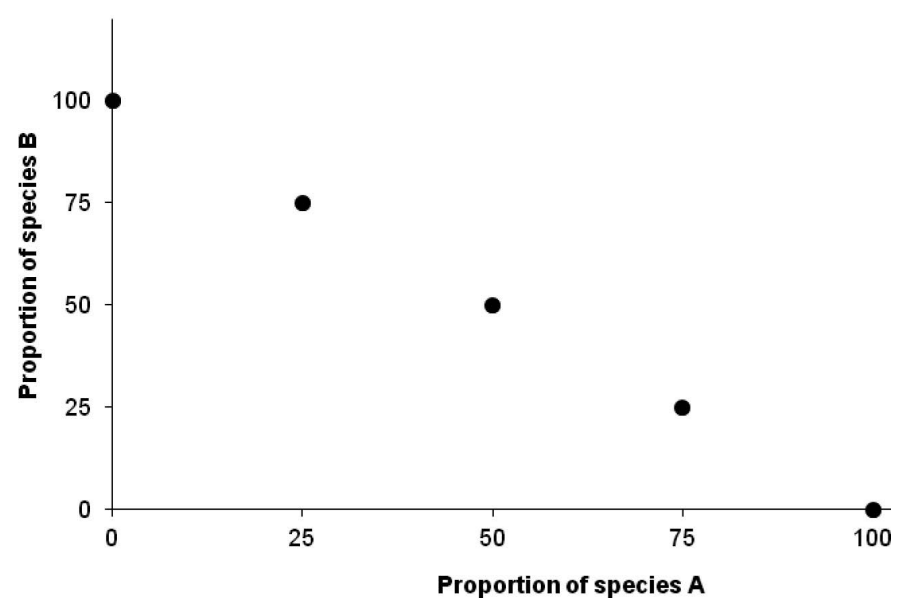

Figure 2. An example of layout (a) and proportions (b) in a replacement series experiment with the use of two plant species.

come some of the criticisms of the additive design (Gibson et al. 1999; Harper 1977; Jolliffe 2000) and is often used to determine which of two species is the most competitive as well as to gain insight into plant-to-plant interactions (Radosevich 1987). Overall plant density is held constant while species proportion is varied. A common approach is to grow plant species in a uniform spatial arrangement at various mixture ratios, such as 75:25, 50:50, and 25:75, along with monocultures of each species (Figures $2 \mathrm{a}$ and $2 \mathrm{~b}$ ). Results are often presented graphically as replacement series diagrams in which absolute or relative yield of each of the two species is plotted against its proportion in mixture (Figure 3). The replacement series is most valuable for providing information about the interactions among species. These interactions can be categorized as negative, positive, or neutral. Relative

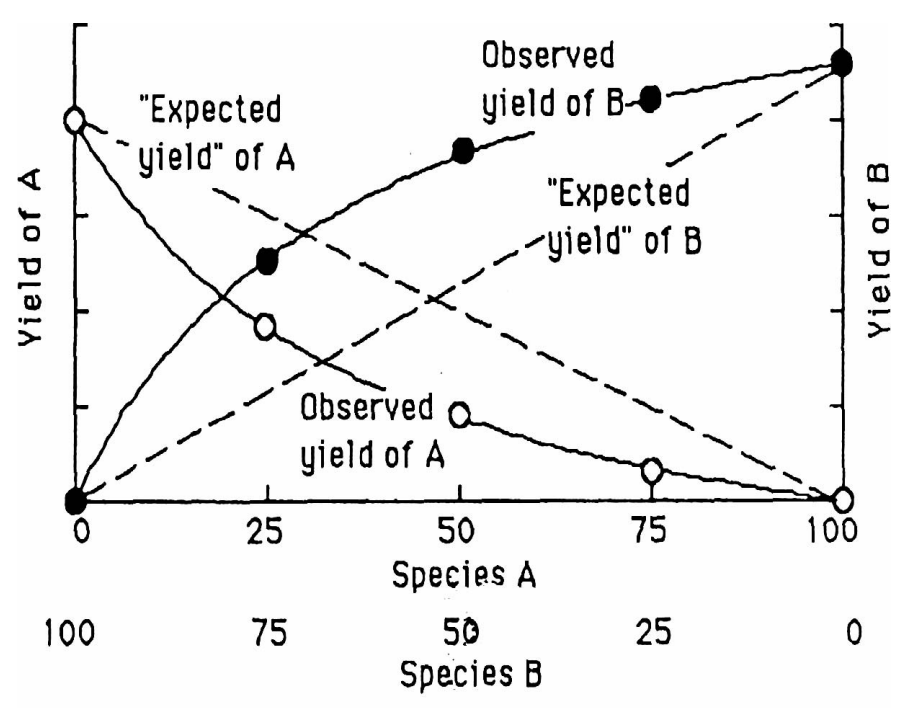

Relative planting density

Figure 3. Hypothetical example of a replacement series diagram showing species yields as functions of their relative planting proportions (Rejmánek et al. 1989).

crowding coefficients and aggressiveness coefficients provide insight on competitive interactions between species (Wang et al. 2006).

There are four possible outcomes for the interaction of a crop species and a weed when grown in a replacement series:

1. The two observed yield responses are straight lines: The ability of each species to interfere with the other is equivalent or the two species are located so far apart that no interaction occurs between them.

2. One response curve is concave and the other is convex: One species is more aggressive than the other (concave response).

3. Both response curves are convex and the total yield of the two species in a mixed stand is less than that of their respective yields in a pure stand: It is a case of mutual antagonism.

4. Both response curves are concave and the total yield of the two species in a mixed stand is greater than that of their respective yields in a pure stand: It is a case of symbiosis.

\section{Advantages}

- Well-suited design to rank the competitive ability of a species under a given set of conditions

- Appropriate design to examine both competition mechanisms and outcomes between crops and weeds (Akey et al. 1991; Wang et al. 2006) and between two weed species (Blackshaw and Schaalje 1993) or weed biotypes (Higgins and Mack 1987; O’Donovan et al. 1999) 


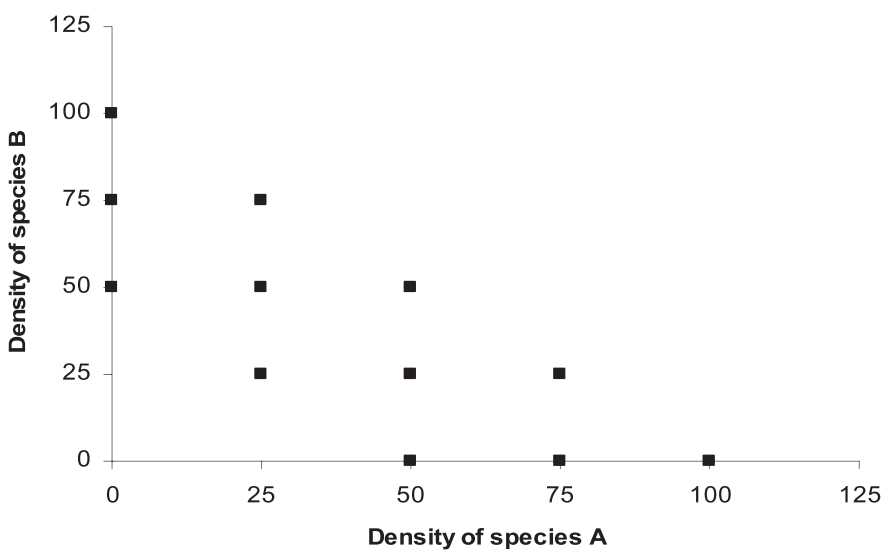

Figure 4. Illustration of a range of relative densities (proportions) and total densities in an addition series experiment. In this case, the experiment is a combination of three replacement series experiments at three different total densities (100, 75, and $50 \%$ of a reference total density).

- Useful in predicting shifts in species composition over time (Conard and Radosevich 1979; Radosevich and Holt 1984)

- Yield ratios can be calculated to describe patterns of resource use and relative aggressiveness among the species (Harper 1977)

\section{Disadvantages}

- Not representative of most field situations where crops occur at a constant density

- Experimental outcomes may depend upon the total plant density selected and specific resource supply conditions used

Addition Series. The addition-series design varies both the density and proportion of each species over a wide range of possible combinations of the two species (Maxwell and O'Donovan 2007; Roush et al. 1989). Addition series can be viewed as a combination of several replacement series at a range of total densities (Figure 4). Another version, called the full factorial or complete addition design (Figure 5), contains all possible combinations of several densities of each species and can be viewed as a series of addition designs at various densities (Cousens 1991). Addition series studies are usually conducted with two species but can accommodate more than two species, although the experiment can become very large.

Separation between intra- and interspecific competition and the estimation of yield loss are based on the reciprocal yield law (Kira et al. 1953):

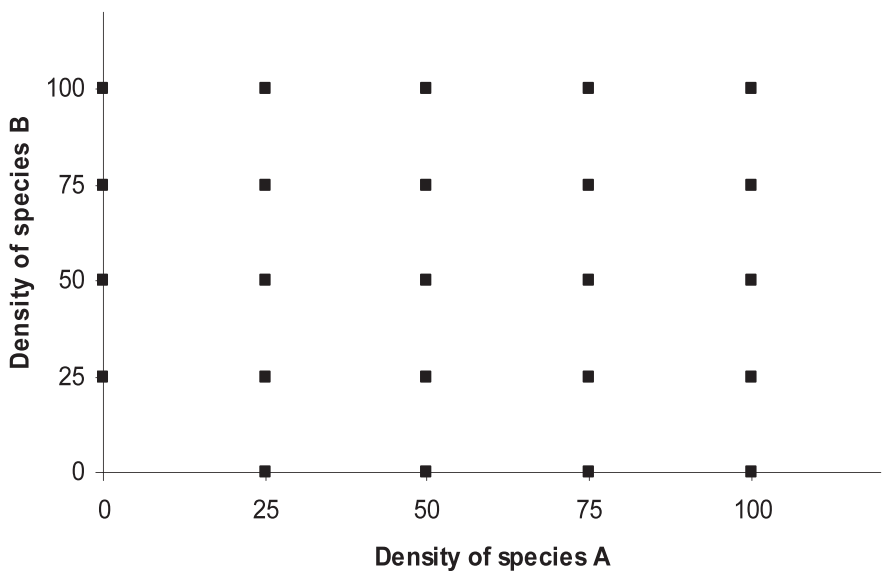

Figure 5. Illustration of a range of relative densities (proportions) and total densities in a complete addition series experiment.

$$
1 / w=a+b d
$$

where $w$ is the mean yield/plant; $d$ the density; $a$ the intersect that can be interpreted as the reciprocal mean yield of an individual plant; and $b$ the slope that measures the effect of intraspecific competition.

Equation 1 can be extended to multiple species mixtures (Spitters 1983):

$$
1 / w_{1}=A_{1}+B_{11} N_{1}+B_{12} N_{2}+\cdots+B_{1 i} N_{i},
$$

where $w_{1}$ is the weight of individual plants of species $1 ; N_{1}, N_{2}$, and $N_{i}$ are the densities of species 1 through $i$; and $A_{1}$ is the intercept representing the reciprocal of maximum plant weight for species 1 . The regression coefficients: $B_{11}$ quantifies the effect of intraspecific competition; $B_{1 i}$ measure the effect of species $i$ on species 1 . These regression coefficients indicate that the yield of any of the species in mixture is influenced by the relative densities of the species that make up a mixed stand. This highlights the significance of proportion or relative density, which are sometimes overlooked in crop-weed competition studies.

Two-Species Mixture Example: Let's assume competition between a crop (species 1) and a weed (species 2). From Equation 1, it can be derived:

$$
\begin{aligned}
& 1 / w_{1}=A_{1}+B_{1,1} D_{1}+B_{1,2} D_{2}, \\
& 1 / w_{2}=\mathrm{A}_{2}+B_{2,2} D_{2}+B_{2,1} D_{1},
\end{aligned}
$$

where $w_{1}$ and $w_{2}$ are the mean plant biomass of the crop and the weed, respectively. The coefficients $B_{1,1}$ and $B_{2,2}$ measure the effects of intraspecific competition. 
The coefficients $B_{1,2}$ and $B_{2,1}$ measure the effects of the weed on the crop, and the crop on the weed, respectively. In this way, intra- and interspecific competition is formally separated. Crop yield (biomass/area) $Y_{1}$ can then be expressed as:

$$
Y_{1}=w_{1} D_{1}=D_{1} / A_{1}+B_{1,1} D_{1}+B_{1,2} D_{2} .
$$

By definition, percent crop loss (CL):

$$
\begin{aligned}
\mathrm{CL}(\%)= & 100-100(\text { yield in mixture }) / \\
& \text { (yield in monoculture }) .
\end{aligned}
$$

By substituting Equations 1 and 5 for yield in monoculture and yield in mixture, Equation 6 becomes

$$
\mathrm{CL}(\%)=100-100\left(Y_{1}\right) /\left[D_{1} /\left(A_{1}+B_{1,1} D_{1}\right)\right]
$$

or

$$
\begin{aligned}
\mathrm{CL}(\%)= & 100\left[1-\left(A_{1}+B_{1,1} D_{1}\right) /\right. \\
& \left.\left(A_{1}+B_{1,1} D_{1}+B_{1,2} D_{2}\right)\right] .
\end{aligned}
$$

Equation 6 shows that the estimate of crop loss depends not only on the weed density but also on crop density.

\section{Advantages}

- Allows separation between intra- and interspecific competition

- Can be used to study competition among more than two plant species

\section{Disadvantages}

- Very large experiments that are laborious and consume many resources (especially under field conditions)

Nelder Design. The Nelder design varies plant density and spatial arrangement in a systematic manner (Harper 1977; Nelder 1962). It consists of a grid of plants grown in an arc or circle arrangement. The amount of space available to each plant changes in a consistent manner over the different regions of the grid. This design is most commonly used to study competition among individuals of a single species, but competition between species can be studied by alternating the placement of species along the arc or spoke such that differing species proportions result. Alternatively, the entire one-species Nelder experiment can be overseeded with a second species allowing examination of interspecific effects. Nelder designs are more frequently used in forestry research than in agricultural studies.

\section{Advantages}

- A relatively small land area is required to examine the effect of many plant densities

- Useful design to study the processes of competition among individual plants

\section{Disadvantages}

- Somewhat difficult and time consuming to establish under field conditions

Neighborhood or Area-of-Influence Design. Neighborhood or area-of-influence designs may be utilized when the response of an individual plant as affected by its proximity to other plants is of primary interest (Harper 1977; Stoll and Weiner 2000; Weiner 1982). The growth or productivity of a target plant is repeatedly measured throughout the growing season as a function of the number, biomass, cover, aggregation, or distance from its neighbors. The target can be a weed or crop plant. The neighborhood design has been used to study crop-weed competition (Bussler et al. 1995) or weed-weed competition (Pacala and Silander 1990). It may be most appropriate in the context of crop-weed competition to study the effects of crop density and planting pattern on resulting weed competition. Lindquist et al. (1994) identified optimal spatial patterns to maximize crop yield in a competitive environment.

\section{Advantages}

- Most useful to study mechanisms of competition

- Could be used to determine optimum crop spatial arrangement to enhance crop competitiveness with weeds

\section{Disadvantages}

- Establishing the various plant proximity treatments is laborious

Critical Period for Weed Control Design. The critical periods of competition design is another widely utilized approach to study crop-weed competition (Hall et al. 1992; Nieto et al. 1968; Weaver and Tan 1987). This period is defined as the time (growth stages) in the life cycle of a crop plant when weeds must be controlled in order to prevent unacceptable yield loss. Two sets of 


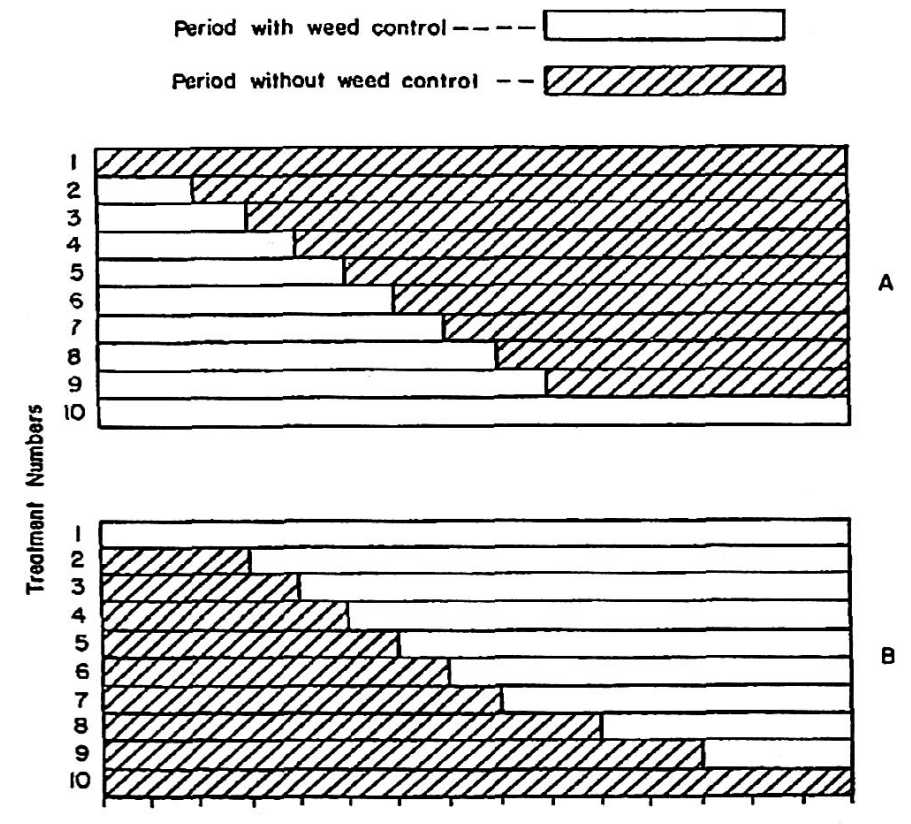

Weeks of ter plonting the crop

Figure 6. Graphic presentation of treatments in critical period of competition experiments (Dawson 1970).

experimental treatments are commonly used in these critical-period studies.

In the first treatment set, the crop is kept weedfree for increasing lengths of time to determine the period that the crop must be kept free of weeds to avoid yield loss (Figure 6A). Beyond this point, mechanical, cultural, or herbicidal weed control measures are no longer needed to achieve maximum crop production. At this time, the crop would have attained sufficient size, stage of development, and competitiveness to minimize the deleterious effects of weeds.

In the second treatment set, weeds are allowed to grow with the crop for increasing lengths of time to determine the maximum period that a crop can tolerate weed infestations before yield losses occur (Figure 6B). In both sets of treatments, the weed intervals may be implemented as a specified number of weeks of growth (3 wk, $6 \mathrm{wk}, 9 \mathrm{wk}$, etc.) or at specified crop growth stages (two leaf, four leaf, six leaf, etc.). Weed removal at these specified intervals can be accomplished by hand weeding or by herbicides.

The critical period of weed control is the combination of these two periods; it is the period during the growing season in which weed competition influences crop yield. Weed presence before and after these times would not be expected to reduce crop yield (Figure 7). For crops with long critical periods, early and effective weed manage-

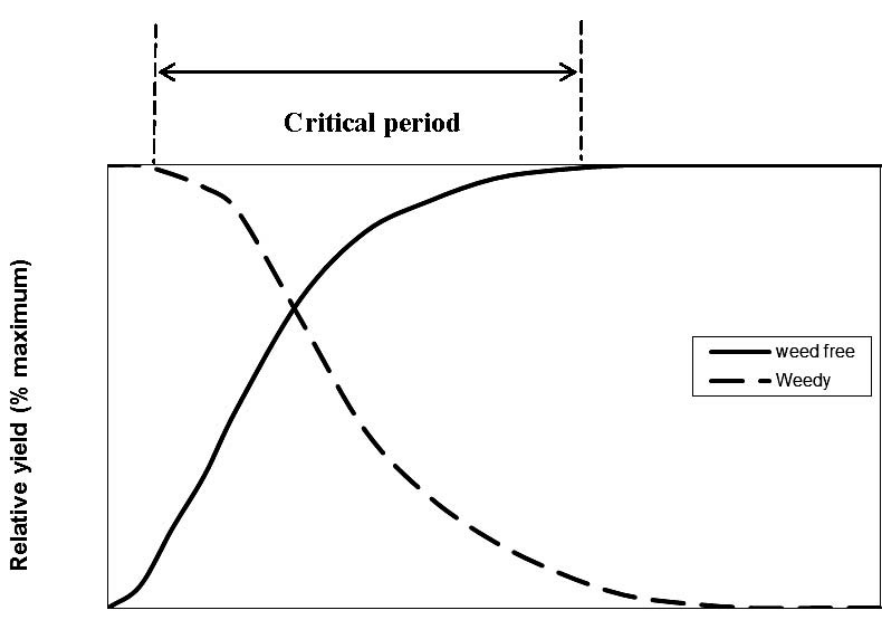

Weeks after emergence

Figure 7. The influence of time of weed emergence or weed removal on percent maximum crop yield and magnitude of the critical period.

ment is a must for approximately 6 to $10 \mathrm{wk}$ to prevent weeds from negatively impacting crop yields. Although critical periods and weed thresholds provide valuable information to producers, it should be noted the scientific community is currently placing more emphasis on controlling all weed seed production as a means of preventing and/ or managing weed resistance. That may mean implementing weed control practices outside the critical period required to protect crop yield.

\section{Advantages}

- Easily established under field conditions where the crop is present at constant density

\section{Disadvantages}

- Usually conducted with only one weed species; thus it is difficult to extend results to farm situations where multiple weed species occur

\section{Experimental Procedures in Competition Studies}

In crop-weed competition studies, once a hypothesis has been framed, the next step is to design a procedure for its evaluation. This process, known as the experimental methodology, consists of four steps: (1) selecting the appropriate materials to test (weed and crop species), (2) specifying the variables to measure (yield, yield loss, biomass, leaf area, growth rate, etc.), (3) selecting the methodology to measure those variables, and (4) specifying the procedure to test the hypothesis. 
In general, the first two steps are fairly easy for a weed scientist to specify. On the other hand, the procedures regarding how the measurements are to be made and how these measurements can be used to accept or reject the hypothesis can be troublesome because of the extreme complexity of factors regulating interactions between crops and weeds. Steps 3 and 4 constitute much of what is generally termed the experimental design, which has the three essential components: (1) estimate of error, (2) control of error, and (3) proper interpretation of results.

Estimate of Error. Consider a weed scientist who wishes to measure the effect of a weed species on yield of a given crop. The researcher lays out two plots of equal size, side by side, and sows one to the crop in a pure stand and the other to the crop-weed mixture. Crop-yield reduction in the mixed stand is then measured relative to the monoculture plot. The methodology, despite its simplicity and commonsense appeal, is flawed, for it presumes that the difference between the two stands is caused by the presence of the weed species and nothing else, which is not true. Even if the mixed stand were planted on both plots, the yield would differ, because other factors, such as soil texture, fertility, and moisture, also affect crop yield. The difference among experimental plots treated alike is called experimental error. Experimental error can be measured only if there are at least two plots planted for a given treatment. Thus, to obtain a measure of experimental error, replication is required. A minimum of four replications is a standard in weed-competition studies. Similarly, results could be biased if the experimental field has a unidirectional fertility or solar gradient. To avoid such bias, replicates must be blocked along the gradient and treatments must be assigned to experimental plots randomly.

Control of Error. The three commonly used techniques for controlling experimental error in weed research are (1) blocking, (2) proper plot technique, and (3) data analysis.

Blocking. Substantial variation can be expected within an experimental field involving weeds as the result of weed genotypic and phenotypic diversity. This variation is compounded by soil and environmental factors that contribute to experimental error. By blocking replicates along soil gradients and by assigning all treatments into each block randomly, variation within block is minimized while variation among is measured and removed from the experimental error.

Proper Plot Technique. It is critical that all other factors besides those considered as treatments be maintained uniformly for all experimental units. For example, in weed critical period experiments where the treatments consist solely of the dates of emergence of weeds, it is required that all other factors such as plant density, soil nutrients, soil water, and all other environmental factors are maintained uniformly for all plots in the experiment. Although this requirement is hard to satisfy, researchers should strive to keep all external factors as homogeneous as possible so that variability among experimental plots within a given block is minimized.

Data Analysis. Proper choice of data analysis can be of great help in situations where blocking alone may not adequately control the experimental error. Covariance analysis can be used for this purpose by reducing the variability among experimental units through adjustment of their values to a common value of the covariates. The covariate is the character whose functional relationship to the primary character is known. For example, in a multispecies competition experiment, the date of emergence of each weed species usually differs. Using this date as the covariate, final weight of individual plants can be adjusted to the value that would have been attained had all species emerged the same day.

Proper Interpretation of Results. An essential feature of controlled experiments is their ability to maintain constant all factors that are not the treatments being assessed. The weed scientist has to bear in mind that this uniformity is both an advantage and a weakness in the sense that it allows the measurement and reduction of experimental error, while at the same time limiting the applicability and generalization of the experimental results. This limitation must always be considered in the interpretation of the results.

Consider the crop-weed competition experiment aimed at determining crop-yield loss due to the competitive effect of a single weed species. Clearly the results of such an experiment are, strictly speaking, applicable only to agroecosystems in which the studied weed species is the only species or is at least the dominant species. However, the 
reality is that most croplands are colonized by several weed species. In addition, the environment surrounding a single experiment can hardly represent the variation over space and time that is so typical of agricultural ecosystems. Consequently, crop-weed competition studies should be conducted for several crop seasons at different locations, on research stations and farm fields, to ensure the applicability of the results over a wide range of environments.

\section{Summary}

Crop-weed competition studies are important because they provide critical information on whether weed control measures are required, and if so, what is the optimal timing to implement control practices to protect crop yield and quality. Additionally, they provide information on the merits of various crop production practices (e.g., crop rotation, higher seeding rates, narrower row spacing) that may improve overall crop competitiveness.

Several experimental designs have been devised to study crop-weed competition. Each design deals with plant density, plant spatial arrangement, and proportion of competing plants in different ways. The choice of experimental design is largely dictated by the hypothesis being tested and the practicality of conducting the experiment in terms of land requirements and labor. Once the experimental design has been selected, then it is critical to outline the procedures to be used carefully, to allow accurate hypothesis testing. This includes determination of what variables to measure, the methodology used to measure those variables, and the selection of appropriate statistical analyses. Proper selection of the experimental design and procedures will ensure a successful crop-weed competition study.

\section{Literature Cited}

Agrow (2003) Agrochemical sales flat in 2002. Agrow: World Crop Protection News. http://ipm.osu.edu/trans/043_141. htm. Accessed November 7, 2012

Akey WC, Jurik TW, Dekker J (1991) A replacement series evaluation of competition between velvetleaf (Abutilon theophrasti) and soybean (Glycine max). Weed Res 31:63-72

Appleby AP, Muller F, Carpy S (2000) Weed control. Pages 687-707 in Muller F, ed. Agrochemicals. New York: Wiley

Ballaré C (1999) Keeping up with the neighbours: phytochrome sensing and other signalling mechanisms. Trends Plant Sci 4:97-102

Ballaré CL, Scopel AL, Sanchez RA (1990) Far-red radiation reflected from adjacent leaves: an early signal of competition in plant canopies. Science 247:329-332
Blackshaw RE (1993) Downy brome (Bromus tectorum) density and relative time of emergence affects interference in winter wheat (Triticum aestivum). Weed Sci 41:551-556

Blackshaw RE, Stobbe EH, Sturko ARW (1981) Effect of seeding dates and densities of green foxtail (Setaria viridis) on the growth and productivity of spring wheat (Triticum aestivum). Weed Sci 29:212-217

Blackshaw RE, Schaalje GB (1993) Density and species proportion effects on interference between redstem filaree (Erodium cicutarium) and round-leaved mallow (Malva pusilla). Weed Sci 41:594-599

Bussler BH, Maxwell BD, Puettmann KJ (1995) Using plant volume to quantify interference in corn (Zea mays) neighborhoods. Weed Sci 43:586-594

Cardina J, Regnier E, Sparrow D (1995) Velvetleaf (Abutilon theophrasti) competition and economic thresholds in conventional- and no-tillage corn (Zea mays). Weed Sci 43:81-87

Casal JJ, Sanchez RA, Deregibus VA (1987) The effect of light quality on shoot extension growth in three species of grasses. Ann Bot 59:1-7

Conard SG, Radosevich SR (1979) Ecological fitness of Senecio vulgaris and Amaranthus retroflexus biotypes susceptible and resistant to atrazine. J Appl Ecol 16:171-177

Cousens R (1985) A simple model relating yield loss to weed density. Ann Appl Biol 107:239-252

Cousens R (1991) Aspects of the design and interpretation of competition (interference) experiments. Weed Technol 5:664-673

Dawson JH (1970) Time and duration of weed infestation in relation to weed-crop competition. Proc South Weed Sci Soc 23:437-440

Dew DA (1972) An index of competition for estimating crop loss due to weeds. Can J Plant Sci 52:921-927

Dieleman A, Hamill AS, Fox GC, Swanton CJ (1996) Decision rules for postemergence control of pigweed (Amaranthus spp.) in soybean (Glycine max). Weed Sci 44:126-132

Dunan CM, Westra P, Schweizer EE, Lybecker DW, Moore FD (1995) The concept and application of early economic period threshold: the case of DCPA in onions (Allium cepa). Weed Sci 43:634-639

Gibson DJ, Connolly J, Hartnett DC, Weidenhamer JD (1999) Designs for greenhouse studies of interactions between plants. J Ecol 87:1-16

Hall MR, Swanton CJ, Anderson GW (1992) The critical period of weed control in grain corn (Zea mays). Weed Sci 40:441-447

Harper JL (1977) The Population Biology of Plants. London, UK: Academic Press

Higgins SS, Mack RN (1987) Comparative responses of Achillea millefolium ecotypes to competition and soil type. Oecologia 73:591-597

Jolliffe PA (2000) The replacement series. J Ecol 88:371-385

Kasperbauer MJ, Karlen DL (1986) Light-mediated bioregulation of tillering and photosynthate partitioning in wheat. Physiol Planta 66:159-163

Kira T, Ogawa H, Sakazaki N (1953) Intraspecific competition among higher plants. I. Competition-yield-density interrelationships in regularly dispersed populations. J Inst Polytech, Osaka City Univ, Ser D 4:1-16

Knezevic SV, Weise SF, Swanton CJ (1994) Interference of redroot pigweed (Amaranthus retroflexus) in corn (Zea mays). Weed Sci 42:568-573

Kropff MJ, Spitters CJT (1991) A simple model of crop loss by weed competition from early observations on relative leaf area of the weed. Weed Res 31:97-105 
Lindquist JL, Rhode D, Puettmann KJ, Maxwell BD (1994) The influence of plant population spatial arrangement on individual plant yield. Ecol Appl 4:518-524

Maxwell BD, O’Donovan JT (2007) Understanding weed-crop interactions to manage weed problems. Pages 17-33 in Upadhyaya MK and Blackshaw RE, eds. Non-Chemical Weed Management: Principles, Concepts and Technology. Oxfordshire, UK: CAB International

Nelder JA (1962) New kinds of systematic designs for spacing experiments. Biometrics 18:283-307

Nieto JN, Brondo MA, Gonzalez JT (1968) Critical periods of the crop growth cycle for competition from weeds. Pest Artic News Summ Sect C 14:159-166

O'Donovan JT, de St. Remy EA, O'Sullivan PA, Dew DA, Sharma AK (1985) Influence of the relative time of emergence of wild oat (Avena fatua) on yield loss of barley (Hordeum vulgare) and wheat (Triticum aestivum). Weed Sci 33:498-503

O'Donovan JT, Newman JC, Blackshaw RE, Harker KN, Derksen DA, Thomas AG (1999) Growth, competitiveness, and seed germination of triallate/difenzoquat-susceptible and -resistant wild oat populations. Can J Plant Sci 79:303-312

Oliver LR (1988) Principles of weed threshold research. Weed Technol 2:398-403

Pacala S, Silander J (1990) Field tests of neighbourhood population dynamic models of two annual weed species. Ecol Monogr 60:113-134

Page ER, Tollenaar M, Lee EA, Lukens L, Swanton CJ (2010) Shade avoidance: an integral component of crop-weed competition. Weed Res 50:281-288

Quail PH (2002) Phytochrome photosensory signaling networks. Nat Rev Mol Cell Biol 3:85-89

Radosevich SA (1987) Methods to study interactions among crops and weeds. Weed Technol 1:190-198

Radosevich SA, Holt J (1984) Weed Ecology: Implications for Vegetation Management. New York: Wiley

Rajcan IR, Swanton CJ (2001) Understanding maize-weed competition: resource competition, light quality and the whole-plant. Field Crops Res 71:139-150

Rejmánek M, GR Robinson, E Rejmánková (1989) Weed-crop competition: experimental designs and models for data analysis. Weed Sci 37:276-284
Roush ML, Radosevich SR, Wagner RG, Maxwell BD, Petersen TD (1989) A comparison of methods for measuring effects of density and proportion in plant competition experiments. Weed Sci 37:268-275

Skinner RH, Simmons SR (1993) Modulation of leaf elongation, tiller appearance and tiller senescence in spring barley by farred light. Plant Cell Environ 16:555-562

Smith H (2000) Phytochromes and light signal perception by plants: an emerging synthesis. Nature 407:5985-5991

Smith H, Whitelam GC (1997) The shade avoidance syndrome: multiple responses mediated by multiple phytochromes. Plant Cell Environ 20:840-844

Spitters CJT (1983) An alternative approach to the analysis of mixed cropping experiments. I. Estimation of competition effects. Neth J Agric Sci 31:1-11

Stoll P, Weiner J (2000) A neighbourhood view of interactions among individual plants. Pages 11-27 in Dieckmann U, Law R, and Metz JAJ, eds. The Geometry of Ecological Interactions: Simplifying Spatial Complexity. New York: Cambridge University Press

Swanton CJ, Weaver S, Cowan P, Van Acker R, Deen W, Shresta A (1999) Weed thresholds: theory and applicability. J Crop Prod 2:9-29

Vitousek PM, Howarth RW (1991) Nitrogen limitation on land and on sea: how can it occur? Biogeochemistry 13:87-115

Walker TW, Syers JK (1976) The fate of phosphorus during pedogenesis. Geoderma 15:1-19

Wang G, McGiffin ME, Jr, Ehlers JD (2006) Competition and growth of six cowpea (Vigna unguiculata) genotypes, sunflower (Helianthus annus), and common purslane (Portulaca oleracea). Weed Sci 54:954-960

Weaver SE, Tan CS (1987) Critical periods of weed interference in transplanted tomatoes and its relation to water stress and shading. Can J Plant Sci 67:575-583

Weaver SE, Ivany JA (1998) Economic thresholds for wild radish, wild oat, hemp-nettle and corn spurry in spring barley. Can J Plant Sci 78:357-361

Weiner J (1982) A neighborhood model of annual-plant interference. Ecology 63:1237-1241

Received April 19, 2013, and approved June 26, 2013. 